\title{
Rare coracoid fractures presenting with superior shoulder suspensory complex injury: A case series
}

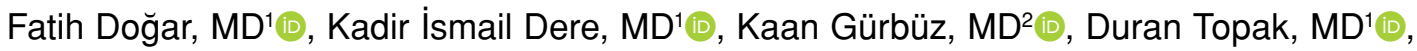

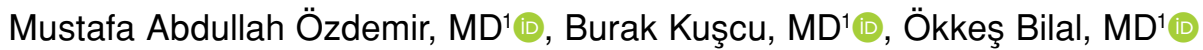 \\ ${ }^{1}$ Department of Orthopedics and Traumatology, Kahramanmaraş Sütçü Imam University, Faculty of Medicine, Kahramanmaraş, Turkey \\ ${ }^{2}$ Department of Orthopedics and Traumatology, Kayseri City Training and Research Hospital, Kayseri, Turkey
}

The coracoid process is an important anatomical landmark serving as an attachment site for the short head of the biceps brachii, coracobrachialis, and pectoralis minor muscles and coracoacromial, coracohumeral, trapezoid, and conoid ligaments. ${ }^{[1]}$ Another important function of the coracoid process is that it contributes to the anterior superior stability of the shoulder joint by forming the coracoacromial arch and the superior shoulder suspensory complex (SSSC). ${ }^{[2,3]}$

Coracoid fractures are usually associated with other fractures and dislocations of the scapula and the shoulder area, and they are occasionally observed after high-energy traumas. ${ }^{[3,4]}$ While coracoid fractures constitute 3 to $13 \%$ of scapular fractures, they constitute $1 \%$ of all fractures and $5 \%$ of shoulder fractures..$^{[1,3-8]}$

Received: June 07, 2021

Accepted: August 18, 2021

Published online: November 19, 2021

Correspondence: Fatih Doğar, MD. Kahramanmaraş Sütçü İmam Üniversitesi Tıp Fakültesi Ortopedi ve Travmatoloji Anabilim Dalı, 46040 Onikişubat, Kahramanmaraş, Türkiye.

E-mail: drfatihdogar@hotmail.com

Doi: $10.52312 / j d r s .2021 .294$

Citation: Doğar F, Dere KI, Gürbüz K, Topak D, Özdemir MA, Kuşcu B, et al. Rare coracoid fractures presenting with superior shoulder suspensory complex injury: A case series. Jt Dis Relat Surg 2021;32(3):804-809.

(92021 All right reserved by the Turkish Joint Diseases Foundation

This is an open access article under the terms of the Creative Commons Attribution-NonCommercial License, which permits use, distribution and reproduction in any medium, provided the original work is properly cited and is not used for commercial purposes (http://creativecommons.org/licenses/by-nc/4.0/).

\section{ABSTRACT}

Although coracoid fractures are rare fractures, their treatment is critical as they form the coracoacromial arch and superior shoulder suspensory complex (SSSC), which are important structures for shoulder biomechanics. In this case series, clinical, radiological, and demographic characteristics of three male patients who received treatment due to coracoid fracture presenting with traumatic injuries were discussed. The fractures were classified according to the Ogawa and Eyres classifications, and fracture fixation was achieved surgically with the cannulated screws. All patients had a right coracoid fracture. The Constant-Murley Score and the Disabilities of the Arm, Shoulder and Hand scores the patients in the final follow-up visit at 12 months were calculated. In conclusion, good clinical and functional outcomes can be achieved by anatomical reduction and fixation through surgery for displaced coracoid fractures presenting with multiple traumatic injuries located in multiple regions of the SSSC.

Keywords: Coracoid, fracture, Ogawa classification, superior shoulder suspensory complex, surgery.

Patients usually present with the complaints of pain in the shoulder area and tenderness in the infraclavicular fossa. ${ }^{[1]}$ Ogawa $^{[5]}$ and Eyres et al. ${ }^{[6]}$ classifications are frequently used for the classification of coracoid fractures. In the Ogawa classification, the fracture is divided into two groups according to the relationship between the location of the fracture and the coracoclavicular (CC) ligament. ${ }^{[5]}$ Ogawa type I fractures are located proximal to the CC ligament, whereas Ogawa type II fractures include fractures distal to the CC ligament. ${ }^{[5]}$ According to the classification made by Eyres et al., ${ }^{[6]}$ there are five types of coracoid fractures. The Eyres type I-III mostly include avulsion fractures, whereas type IV and V are more severe fractures involving the base of the coracoid process. ${ }^{[6]}$ 
There is no consensus on the treatment of coracoid fractures. ${ }^{[1]}$ Most isolated coracoid fractures that are non-displaced or minimally displaced are treated conservatively. ${ }^{[4,7]}$ However, surgery should be considered, when multiple injuries are involved. There is no consensus on the type of surgical treatment and implant selection for coracoid fractures, and fixation can be achieved with cannulated screws, tubular plate, or reconstruction plate..$^{[4,8,9]}$

In this case series, we present the clinical and radiological outcomes of surgery for rare coracoid fractures accompanied by SSSC injuries in multiple locations.

\section{CASE REPORT}

In our clinic, three patients with coracoid fractures presenting with traumatic injuries who were treated between January 2020 and May 2021 were examined clinically, radiologically, and demographically. All patients were operated in the beach chair position and under general anesthesia. In one patient, a posterior incision parallel to the spina scapula was used for the acromion, and a deltopectoral incision was used for the coracoid. In the other two patients, a single incision was performed owing to an accompanying clavicular fracture. Two guidewires were advanced with $15^{\circ}$ to $20^{\circ}$ medial and $30^{\circ}$ to $45^{\circ}$ posterior inclinations after the reduction of the coracoid process. After confirmation using fluoroscopy, it was drilled with a $2.7-\mathrm{mm}$ drill and fixation was achieved with two cannulated compression headless screws of $3.5 \mathrm{~mm}$ in appropriate length. The patients and their families were informed that data from the case would be submitted for publication, and gave their consent.

Case 1- A 20-year-old male patient presented to the emergency room due to a fall from a height of 10 meters. The patient had distal clavicular,
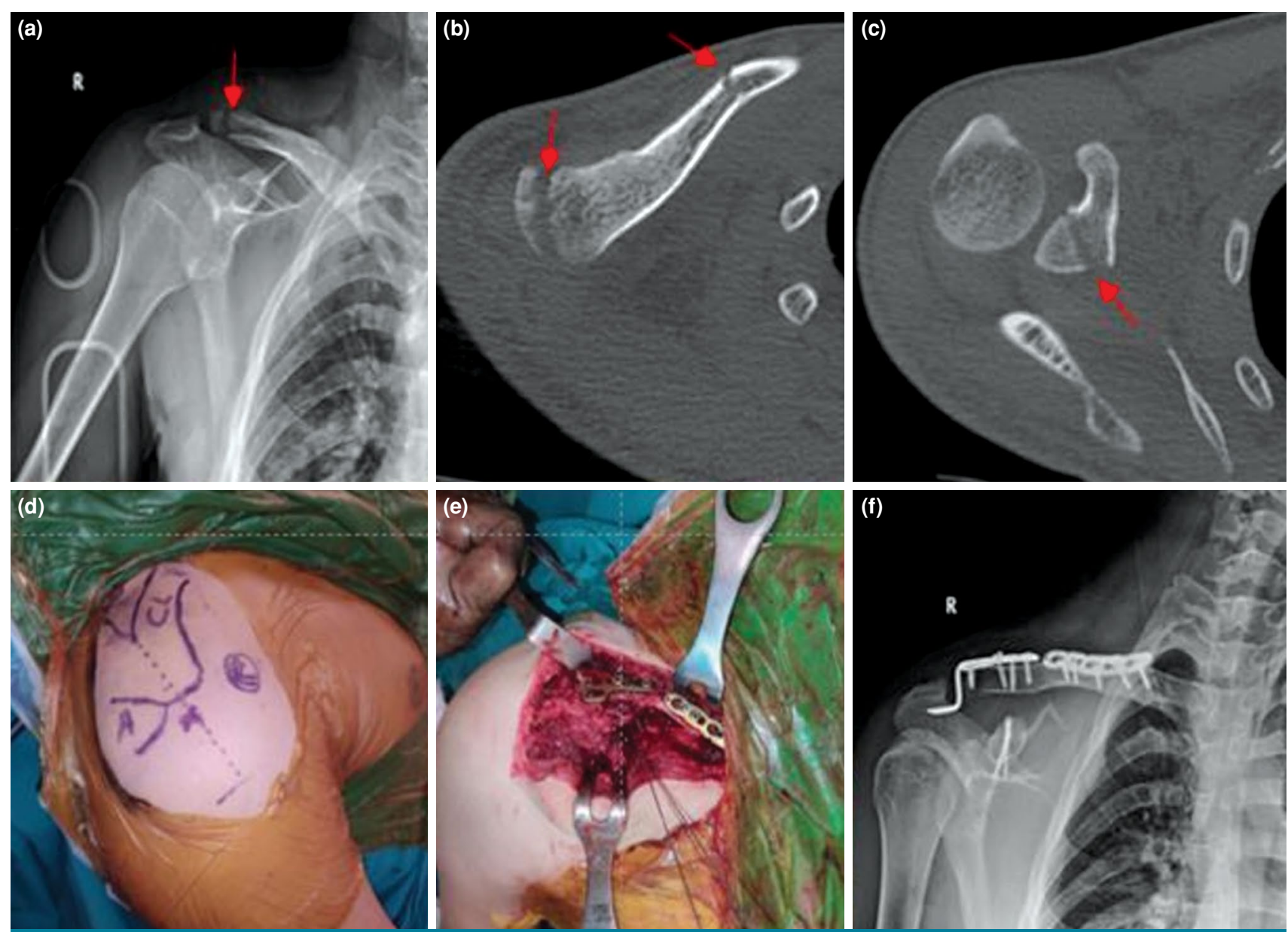

FIGURE 1. (a) Preoperative X-ray and $(\mathbf{b}, \mathbf{c})$ computed tomography, $(\mathbf{d}, \mathbf{e})$ intraoperative and (f) postoperative X-ray images of Case 1. 


\begin{tabular}{|c|c|c|c|}
\hline \multicolumn{4}{|c|}{ TABLE I } \\
\hline Variable & Case 1 & Case 2 & Case 3 \\
\hline Age (year) & 20 & 15 & 31 \\
\hline Side & Right & Right & Right \\
\hline Sex & Male & Male & Male \\
\hline Etiology & Falling & Traffic accident & Falling \\
\hline \multicolumn{4}{|c|}{ Classifications of coracoid fracture } \\
\hline Ogawa & 1 & 1 & 1 \\
\hline Eyres & 4 & 4 & 5 \\
\hline Treatment & ORIF & ORIF & ORIF \\
\hline Time of surgery (day) & 8 & 2 & 4 \\
\hline \multicolumn{4}{|l|}{ SSSC injury } \\
\hline Coracoid & + & + & + \\
\hline Distal clavicula & + & - & - \\
\hline $\mathrm{AC}$ joint & - & + & - \\
\hline Acromion & + & - & + \\
\hline CMS & 80 & 91 & 87 \\
\hline DASH score & 15.8 & 9.2 & 13.2 \\
\hline
\end{tabular}

clavicle shaft, and non-displaced acromion fractures accompanied by the right coracoid fracture (Figure 1a-c). After fixing the segmental clavicular fractures with a $3.5-\mathrm{mm}$ clavicle anatomical plate and a hook plate with an anterior single incision made to the clavicle, the coracoid process was
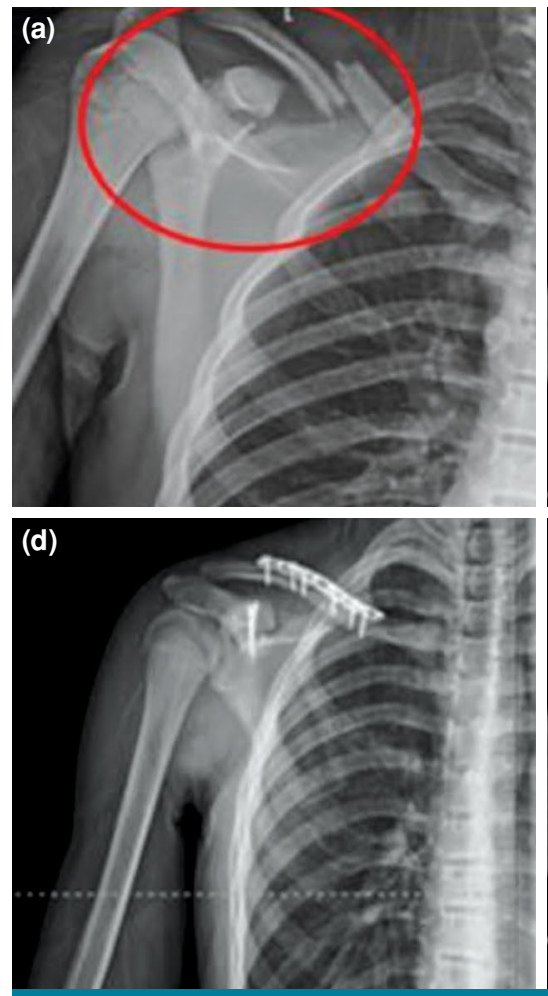
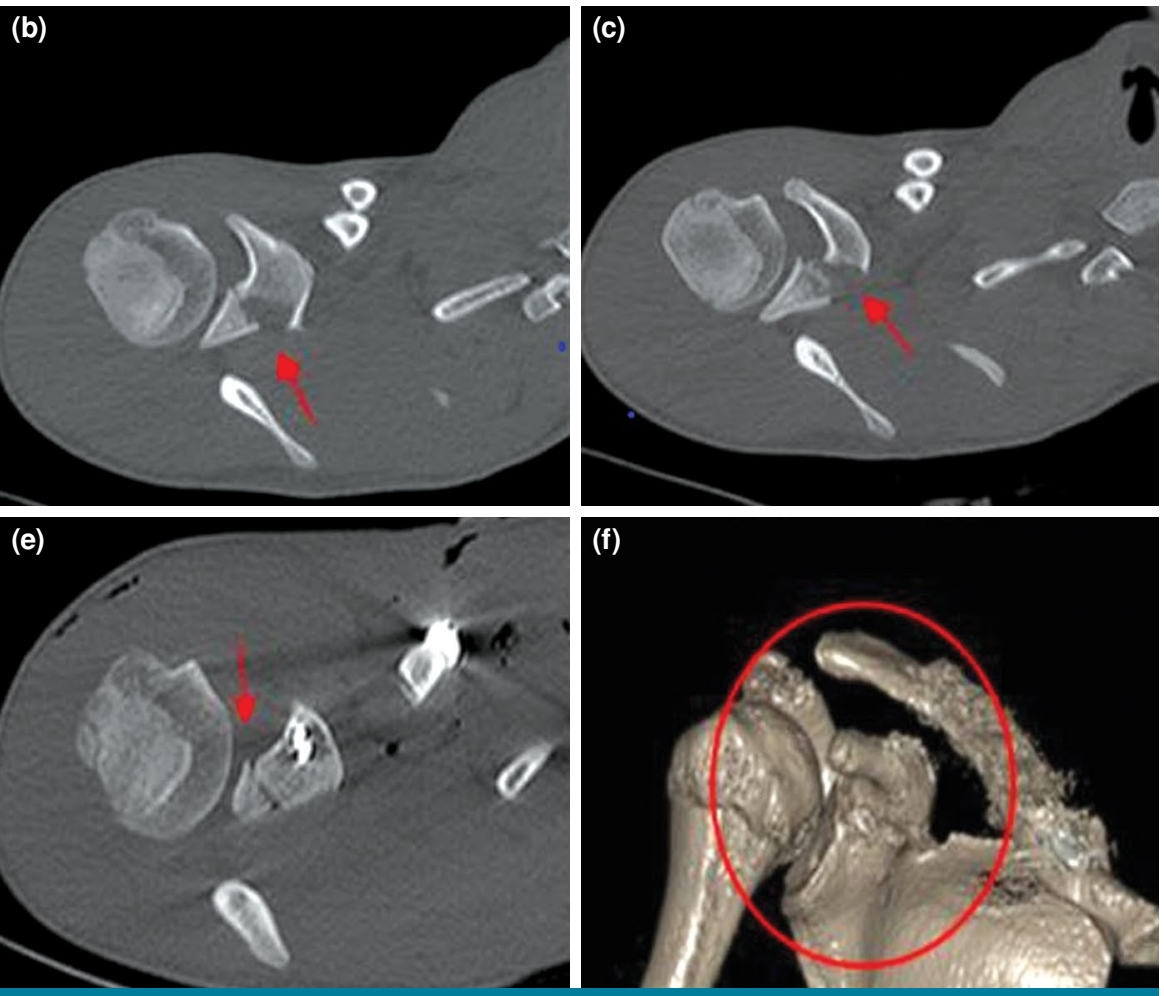

FIGURE 2. (a-c) Preoperative and (d) postoperative X-ray and (e,f) computed tomography images of Case 2. 

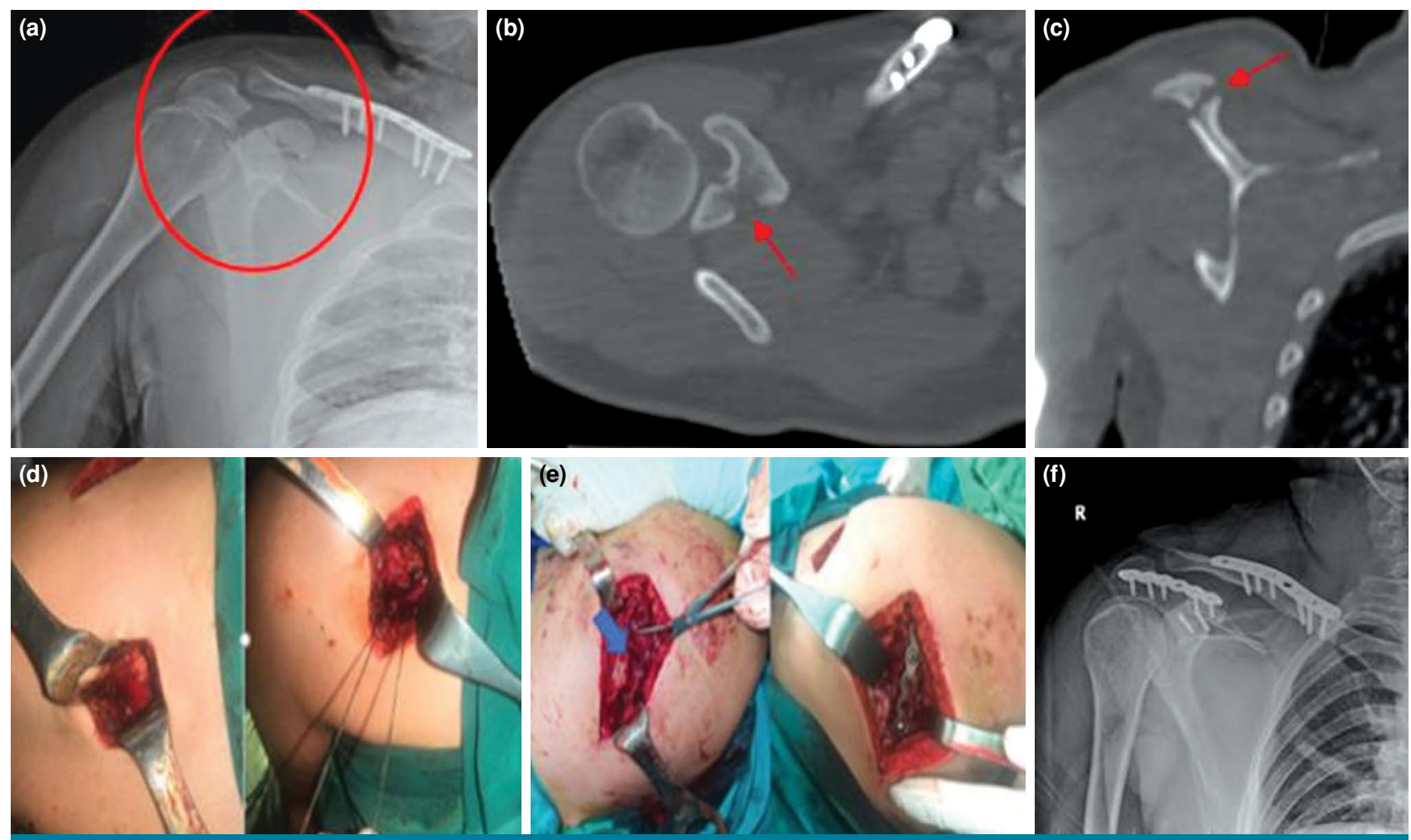

FIGURE 3. (a) Preoperative X-ray and (b, c) computed tomography, (d, e) intraoperative acromion and coracoid exposure and (f) postoperative $\mathrm{X}$-ray images of Case 3.

reduced and fixed with two cannulated compression headless screws (Figure 1d-f). Additionally, the SSSC ring of the patient was damaged in three different regions (Table I).

Case 2- A 15-year-old male patient was brought to the emergency room after being involved in a traffic accident as a pedestrian. The patient had a displaced clavicular fracture and type II acromioclavicular (AC) joint injury accompanied by the coracoid fracture (Figure 2a-c). After the clavicle was reduced with a single anterior incision, fixation was performed using a $3.5-\mathrm{mm}$ clavicle anatomical plate and a screw. The coracoid process was, then, reduced and fixed with two cannulated compression headless screws (Figure 2d-f). The SSSC ring of the patient was damaged in two different regions (Table I).

Case 3- A 31-year-old male patient was brought to the emergency room due to a fall from a height. The patient had an acromion fracture accompanying the coracoid and scapular spine fractures. The patient was operated for a clavicular fracture two years ago due to fall from a height (Figure 3a-c). Unlike other two patients, different incisions were used for the coracoid and acromion fractures (Figure 3d-h). After fixing the acromion fracture with a $3.5-\mathrm{mm}$ reconstruction plate, the coracoid fracture was fixed with two cannulated compression headless screws (Figure 3g). Furthermore, The SSSC ring of the patient was damaged in two different regions (Table I).

The median age of all three patients was 22 (range, 15 to 31) years, and the median follow-up was 12 (range, 10 to 14) months. All patients had a right coracoid fracture. The median time until surgery was 4.6 (range, 2 to 8 ) days, and surgical intervention was not performed on the day of injury due to accompanying injuries (Table I). All patients had injuries in the SSSC ring at two or more regions (Table I). The Constant-Murley Scores (CMS) and Disabilities of the Arm, Shoulder and Hand (DASH) scores of the patients are presented in Table I.

All the patients were admitted to the emergency department after sustaining high-energy trauma: two patients after a fall from a height and one patient after being involved in a road traffic accident as a pedestrian. All patients had multiple traumatic injuries accompanied by the coracoid fracture (Table II). 


\begin{tabular}{|c|c|c|c|c|}
\hline \multicolumn{5}{|c|}{$\begin{array}{c}\text { TABLE II } \\
\text { Injuries presenting with a coracoid fracture }\end{array}$} \\
\hline Variable & Case 1 & Case 2 & Case 3 & Total \\
\hline AC joint injury & + & + & - & 2 \\
\hline \multicolumn{5}{|l|}{ Clavicula fracture } \\
\hline Proximal & - & - & - & 0 \\
\hline Shaft & + & + & - & 2 \\
\hline Distal & + & - & - & 1 \\
\hline \multicolumn{5}{|l|}{ Scapula fracture } \\
\hline Acromion & + & - & + & 2 \\
\hline Scapular spine/superior margin & - & - & + & 1 \\
\hline Shoulder dislocation & - & - & - & 0 \\
\hline Rib fracture and associated lung injury & + & - & + & 2 \\
\hline Head and neck injury & + & + & - & 2 \\
\hline Vertebral injury & + & - & + & 2 \\
\hline Other extremity injury & + & - & - & 1 \\
\hline AC: Acromioclavicular. & & & & \\
\hline
\end{tabular}

\section{DISCUSSION}

Coracoid fractures are very rare among shoulder girdle fractures, and they occur after high-energy trauma. ${ }^{[1,10]}$ As coracoid fractures are usually nondisplaced or minimally displaced, they may be overlooked on routine X-ray examinations. ${ }^{[10-12]}$ Therefore, special direct radiograms, computed tomography and magnetic resonance imaging are frequently used in the diagnosis. ${ }^{[10,12,13]}$

Ogawa et al. ${ }^{[5]}$ classified coracoid fractures based on clinical and functional characteristics. This classification was originally developed considering the relationship between the fracture and attachment sites of the CC ligament, and the fractures were divided into two types. While the connection between the scapula and the clavicle is disrupted in type I fractures, it is preserved in type II fractures. ${ }^{[14]}$ Although controversy still exists regarding the underlying mechanism of coracoid fractures, it has been proposed in many reports that type I fractures are caused by a lateral trauma to the shoulder. ${ }^{[4,6,14]}$ The patients in our study had type I fractures and, for all three patients, the mechanism of injury is consistent with the literature.

Superior shoulder suspensory complex was first described by $\operatorname{Goss}^{[2]}$ in 1993. It consists of the glenoid, coracoid process, CC ligament, distal clavicle, AC joint, and acromion process. According to Goss, ${ }^{[2]}$ SSSC is a dynamic structure, which establishes a stable relationship between the axial skeletal system and the upper extremity. It has been argued that recovery may be delayed and functional outcomes would be poor in injuries involving two or more sites of SSSC. ${ }^{[3,10]}$ Two patients in our study had injuries in two SSSC sites, and one patient had injuries in three SSSC sites, and the outcomes in these patients were similar to that reported in the literature.

Ogawa type I coracoid fractures are important for two reasons. First, the connection between the scapula and the clavicle and the continuity of SSSC are damaged. Second, the coracoacromial arch is disrupted, leading to both subcoracoid compression and subacromial compression. Therefore, it is important to reconstruct the scapuloclavicular junction and reduce and fix the coracoid process with an aim of restoring the coracoacromial arch. ${ }^{[14]}$ Therefore, the reduction and anatomical fixation of the coracoid process was performed in all three patients.

In Ogawa type I and II fractures, coracoid fractures can be exposed and reduction and fixation can be achieved in the beach chair position using an anterior deltopectoral approach. ${ }^{[8]}$ Moreover, it is recommended that the patient should be fully relaxed and, thus, no difficulty is experienced during reduction. ${ }^{[8]}$ For our patients, general anesthesia and complete muscle relaxation were provided by the anesthesia team during surgery. In one patient, the coracoid fracture was fixed using an anterior deltopectoral approach, whereas the other two 
patients had an accompanying clavicular fracture for which a single incision was made on the anterior shoulder.

Many reports in the literature have shown that non-displaced coracoid fractures can be managed conservatively; however, surgery is recommended in patients performing heavy work activities and in those sustaining sports injuries, ${ }^{[4,7-9,11,14]}$ since Goss ${ }^{[15]}$ reported poor outcomes, if coracoid fractures were not fixed surgically in such patients. In surgical treatment, coracoid fixation can be made with cannulated screws, tubular plate, or reconstruction plate. Coracoid reduction and anatomical fixation were performed with compression screws in all three patients in this study. In addition, the DASH scores of the patients in the final follow-up visit at 12 months were found to be similar to that reported in the literature, and the CMS scores were found to be better, unlike the literature. ${ }^{[1,8,16]}$

In the postoperative follow-up and final controls of our patients, there was no limitation in shoulder joint movements, full range of motion was achieved, and good functional and clinical outcomes were obtained.

In conclusion, coracoid fractures with SSSC injury in multiple regions are uncommonly injuries after high-energy trauma and are usually associated with other injuries. For the definitive diagnosis of coracoid fractures, a detailed radiological imaging such as computed tomography and magnetic resonance imaging should be definitely performed in addition to a detailed physical examination, and the presence of additional traumatic injuries should not be overlooked. Good clinical and functional outcomes can be achieved by anatomical reduction and fixation with surgery in case of displaced coracoid fractures accompanied by multiple traumatic injuries involving two or more regions of the SSSC.

\section{Declaration of conflicting interests}

The authors declared no conflicts of interest with respect to the authorship and/or publication of this article.

\section{Funding}

The authors received no financial support for the research and/or authorship of this article.

\section{REFERENCES}

1. van Doesburg PG, El Saddy S, Alta TD, van Noort A, van Bergen CJA. Treatment of coracoid process fractures: A systematic review. Arch Orthop Trauma Surg 2021;141:1091-100.

2. Goss TP. Double disruptions of the superior shoulder suspensory complex. J Orthop Trauma 1993;7:99-106.

3. $\mathrm{Wu} \mathrm{K}, \mathrm{Wu} X \mathrm{X}$, Zha XL, Wang QG. Anatomic restoration of triple disruption of the superior shoulder suspensory complex: A case report and review of the literature. Orthop Surg 2020;12:1526-30.

4. Knapik DM, Patel SH, Wetzel RJ, Voos JE. Prevalence and management of coracoid fracture sustained during sporting activities and time to return to sport: A systematic review. Am J Sports Med 2018;46:753-8.

5. Ogawa K, Yoshida A, Takahashi M, Ui M. Fractures of the coracoid process. J Bone Joint Surg [Br] 1997;79:17-9.

6. Eyres KS, Brooks A, Stanley D. Fractures of the coracoid process. J Bone Joint Surg [Br] 1995;77:425-8.

7. Galvin JW, Kang J, Ma R, Li X. Fractures of the coracoid process: Evaluation, management, and outcomes. J Am Acad Orthop Surg 2020;28:e706-e715.

8. Hill BW, Jacobson AR, Anavian J, Cole PA. Surgical management of coracoid fractures: Technical tricks and clinical experience. J Orthop Trauma 2014;28:e114-22.

9. Ogawa K, Matsumura N, Ikegami H. Coracoid fractures: Therapeutic strategy and surgical outcomes. J Trauma Acute Care Surg 2012;72:E20-6.

10. Badam VK, Harsha TSS, Sankineani SR, Rachakonda KR, Bodanki C, Reddy AVG. Triple disruption of the superior shoulder suspensory complex - a case report. J Orthop Case Rep 2019;9:39-42.

11. Mohammed H, Skalski MR, Patel DB, Tomasian A, Schein AJ, White EA, et al. Coracoid process: The lighthouse of the shoulder. radiographics 2016;36:2084-101.

12. Wu K, Wu XM, Zha XL, Wang QG. Anatomic restoration of triple disruption of the superior shoulder suspensory complex: A case report and review of the literature. Orthop Surg 2020;12:1526-30.

13. Li CH, Skalski MR, Matcuk GR Jr, Patel DB, Gross JS, Tomasian A, et al. Coracoid process fractures: Anatomy, injury patterns, multimodality imaging, and approach to management. Emerg Radiol 2019;26:449-58.

14. Ogawa K, Ikegami H, Takeda T, Watanabe A. Defining impairment and treatment of subacute and chronic fractures of the coracoid process. J Trauma 2009;67:1040-5.

15. Goss TP. The scapula: Coracoid, acromial, and avulsion fractures. Am J Orthop (Belle Mead NJ) 1996;25:106-15.

16. Plachel F, Schanda JE, Ortmaier R, Auffarth A, Resch H, Bogner R. The "triple dislocation fracture": Anterior shoulder dislocation with concomitant fracture of the glenoid rim, greater tuberosity and coracoid process-a series of six cases. J Shoulder Elbow Surg 2017;26:e278-e285. 